\title{
Laboratory Simulation of Irrigation-Induced Settlement of Collapsible Desert Soils Under Constant Surcharge
}

\author{
Ramesh Vandanapu $\cdot$ Joshua R. Omer $\cdot$ Mousa F. Attom
}

Received: 24 October 2016/Accepted: 14 June 2017/Published online: 19 June 2017

(C) The Author(s) 2017. This article is an open access publication

\begin{abstract}
The heterogeneous nature of soil as a load bearing material, coupled with varying environmental conditions, pose challenges to geotechnical engineers in their quest to characterize and understand ground behavior for safe design of structures. Standard procedures for checking bearing capacity and settlement alone may sometimes be insufficient to achieve an acceptable degree of durability and in-service performance of a structure, particularly under varying environmental conditions, whether natural or manmade. There exists a wide variety of problematic soils that exhibit swelling, shrinkage, dispersion and collapse characteristics occasioned by changes in moisture content. Specific examples are collapsible soils, which occur mainly in arid and semi-arid regions, are generally capable of resisting fairly large loads in the dry condition but suffer instability and significant strength loss when in contact with water. A number of case studies in the United Arab Emirates were
\end{abstract}

R. Vandanapu $(\bowtie) \cdot$ J. R. Omer

School of Civil Engineering and Construction, Kingston

University London, London, UK

e-mail: K1452539@kingston.ac.uk;

ramesh.vandanapu@gmail.com

R. Vandanapu

Amity University, Dubai, UAE

M. F. Attom

Department of Civil Engineering, American University of

Sharjah, Sharjah, UAE examined, where lightly loaded structures such as boundary walls, pavements and footpaths had been built on ground overlying collapsible soil strata. Sustained irrigation of the dry landscapes was found to have caused uneven settlement of the collapsible soils leading to continuous distress to the structures as evident from cracking and deformation. To help address the problem, an opportunity has been taken to develop a laboratory method of simulating the loaded behavior of collapsible soils in varying situations and to measure its deformation at constant surcharge and ground water infiltration rates. Finally, relationships were developed to estimate the time and magnitude of settlement, if thickness of collapsible soil is known.

Keywords Collapsible soil · Laboratory simulation · Deformation · Plate loading test

\section{Introduction}

Collapsible soils are found in many parts of the world such as USA, Central and South America, China, Africa, Russia, India and the Middle East (Murthy 2010). Collapsible soils behave interestingly in that they may be competent as load bearing media in certain situations yet in other situations they present special challenges to engineers (Rezaei et al. 2012). Such soils are usually arid and semi-arid sands 
consisting primarily of silt sized particles (Kalantari 2012) and may be susceptible to failure when subjected to water ingress from intermittent precipitation or deliberate water disposal. This is because collapsible soils suffer instability and structural breakdown when in contact with water. Furthermore, due to the high evaporation rate of soil moisture in dry regions, any underlying collapsible soil strata do not have sufficient time to consolidate under the in situ stresses (Pye and Tsoar 1990). Collapsible soils are generally characterized by their natural dryness, openness in structure and high porosity (Noutash et al. 2010). The structure of a collapsible soil strongly influences its mechanical properties as is true for other soil types (Leroueil and Vaughan 1990; Wesley 1990).

Jotisankasa (2005) stated that wetting of collapsible soil, through whatever mechanisms, coupled with loading causes a significant reduction in volume followed by structural collapse. A direct consequence of this is settlement and differential settlement of any structures founded on such soils, which undesirably lose much of their friction component of shear strength. In fact, with or without loading, increase in moisture content cause collapsible soils to exhibit abrupt changes in both volume and strength and this is markedly significant when the degree of saturation is above $50 \%$. Nonetheless, partial collapse behavior of such soils can take place even without full saturation, as reported by Houston et al. (1993) and Abbeche et al. (2010), although other workers for example (Houstan et al. 2002) noted the total collapse of certain soils at given stress level requires a state of full saturation. Water ingress, by whatever means, into collapsible soil strata causes the groundwater table to rise. In urbanized arid/semi-arid sites, water from pipeline leakages, surface irrigation activities and industrial effluents can also percolate deeply into beds of collapsible soils underlying the site. It should be understood that the term "collapsible soils" does not mean a particular soil type but rather a whole variety of soils that are susceptible to structural collapse and examples include wind-blown sand, loess or alluvial soil types (Kalantari 2012). These soils are generally found in an unsaturated state in their natural condition (Zhu and Chen 2009). Other than effects of water, another cause of soil structure collapse is reduction in the strength of the bonding between soil particles, e.g. in loosely cemented sands where the cementing material is liable to softening and weakening by water. Even though it is difficult to predict the behavior of soils that exhibit collapse under unexpected or undesirable water ingress, many researchers have undertaken laboratory tests (Holtz and Hilf 1961; Jennings and Knight 1975; Jasmer and Ore 1987; Anderson and Riemer 1995; Reznik 2007; Gaaver 2012; Kalantari 2012; Rezaei et al. 2012) and field tests (Reznik 1993; Houston et al. 1995) in an attempt to identify certain characteristics of such soils. Among the most significant articles reviewed so far, only a small number are directly related to the current research and are summarized below.

\subsection{Laboratory Tests}

Holtz and Hilf (1961) suggested that loess-like soils are vulnerable to collapse when they have high void ratios and are saturated to the extent that their moisture content exceeds the liquid limit. A graph was developed for use in identifying whether or not a soil is likely to exhibit collapse behavior. Use of the graph requires knowledge of just two basic properties: dry density and liquid limit. In regions like UAE, where the current research is underway, most soils are silty sands that are either non-plastic or possess little or negligible plasticity. Thus, the procedure suggested by Holtz and Hilf (1961) may not be useful in the region of concern.

Anderson and Riemer (1995) used tri-axial equipment to perform constant-shear-drained (CSD) tests on uniformly graded sand and an undisturbed clayey alluvial soil. The test results showed that the collapse potential was related to the stress path, knowledge of which is necessary to accurately predict the collapse potential of such a soil.

Reznik (2007) developed equations to estimate the structural pressure $\left(\sigma_{s z}\right)$ as a function of the degree of saturation (S) using oedometer test results reported by various researchers. 'Structural pressure' value is defined as stress at separation 'points' between elastic and plastic states of any soil (including collapsible soils) under loading. Soil collapse was observed to start when the applied stress exceeded the soil structural pressure values. This led to conclusion that the collapsibility of soil is a non-elastic deformation.

Gaaver (2012) conducted tests on various disturbed and undisturbed soils in an effort to identify the nature of the soils and possible methods of ground improvement. Equations were developed for predicting 
collapse potential of soil, based on determination of the initial moisture content of the soil from lab tests. A new parameter RFSR (reduction factor in shearing resistance) was introduced and could be calculated if the initial moisture content of the soil is known, thereby enabling estimation of the reduction in bearing capacity. In UAE, due to hot climate mostly throughout the year, soils are very dry above groundwater table and thus moisture contents are too low. In view of collecting samples via boreholes for determination of moisture content, the drilling fluids being used will significantly alter the moisture content of soil thereby making it difficult to obtain samples in their true natural state.

One disadvantage of the strategies in the above mentioned researchers is the reliance on collecting undisturbed samples and carrying out time-consuming measurements such as oedometer and tri-axial tests. Another disadvantage is that it would be extremely difficult to obtain undisturbed and truly representative soil samples of cohesion-less silty sands particularly for UAE ground conditions. Therefore it can be commented that whilst the previously reported research is promising for the purpose of assessing whether a soil is collapsible and its degree of collapsibility, it does not closely represent actual field situations. This is because of not taking into account the effects of water ingress, groundwater influence and most significantly the influence of surcharge stresses due to structures resting over the soil in question.

\subsection{Field Tests}

Reznik (1993) conducted plate load tests on collapsible soils at a location in south-western Ukraine by simulating the water flow conditions that were consistent with those observed beneath nearby real structures, where rapid increase of settlements occurred due to uncontrolled wetting of soils. A parameter called the proportionality limit $\left(\mathrm{P}_{\mathrm{pr}}\right)$ was introduced and is defined to represent the maximum pressure corresponding in the linear part of the loadsettlement curve obtained from plate load test. Values of the $\mathrm{P}_{\mathrm{pr}}$ obtained for collapsible soils were found to decrease with increase in water content. It was observed that the degree of saturation of soils under structures due to accidental wetting rarely exceeded $70-80 \%$. Additionally the degree of saturation calculated after conducting the plate load test including wetting was found to be always below $80 \%$. The findings indicated that the load testing technique applied for the collapsible soils was reasonable for design purposes.

Houston et al. (1995) developed an in situ test named 'downhole collapse test' and conducted a series of tests at a site known to exhibit wetting induced collapse. The test was performed in a borehole with load being applied to the plate at the bottom of the borehole. Water was introduced in the test and loadsettlement response of the soil monitored. Using data from all tests, equations were developed thereof and used to estimate the collapse induced by wetting.

Field tests conducted by the two researchers mentioned above attempt to replicate the field conditions and the results would seem realistic for use in geotechnical design. Despite this advantage, such field replicating tests suffer one drawback in that they are laborious and often not cost-effective for some infrastructural projects. Thus the alternative of laboratory tests is still attractive to geotechnical designers provided that there is sufficient modification to create test conditions which simulate reality as closely as possible.

In this research work, the primary aim is to develop a deeper understanding of the behavioral characteristics of collapsible soil and to develop predictive methods together with appropriate parameter values to increase safety and economy in geotechnical design. This work concentrates mainly on laboratory testing of collapsible soils to simulate the effects of water infiltration due to irrigation of landscapes underlain by collapsible soil layers in arid/semi arid environments.

\section{Timeliness and Significance of the Current Research Work}

As already stated, many researchers have attempted to use laboratory and field methods in characterizing collapsible soils, however most of the methods have disadvantages in that they are time consuming and resource intensive. In addition, the methods do not adequately account for the effects of water ingress into soil, yet this is an important consequence of drip irrigation, pipeline leakage and precipitation. Also, field tests are considerably more expensive than laboratory tests as direct sources of design parameters for substructures built on problematic soils such as 
collapsible soils. Therefore, as a better alternative, a carefully designed laboratory simulative test seems plausible as a method of developing empirical parameters for use in geotechnical design for structures built on over collapsible soil strata.

\section{Experimental Study}

In the current research work, it was planned to conduct plate load tests (BS 1377-9:1990) on collapsible soil in a custom designed tank of sufficiently large dimensions, to minimize boundary effects on the stressed zone of soil underneath a loaded plate lying on the soil surface. The tests include introduction of variable water table in the sand tank as well as controlled water infiltration rate to enable simulation of drip irrigation from which water would percolate deeply into underlying strata of collapsible soils supporting structures. The primary purpose of the tests is to understand underlying mechanisms and develop comprehensive data that would be used to formulate predictive equations for rates of settlement of collapsible soil, as functions of several variables such as (1) thickness of collapsible layer, (2) its depth from ground level, (3) groundwater regime. All tests were conducted at controlled infiltration rates and at specified magnitudes of surcharge loading.

\subsection{Methodology}

A number of case studies of structural damage examined in the UAE by Vandanapu et al. (2016) clearly showed structural distresses in lightly loaded structures such as boundary walls, hard landscapes, footpaths and pavements adjacent to areas under drip irrigation. No signs of distresses were noticed in larger structures such as residential houses and office buildings as most of them were founded on deep piles unaffected by superficial strata of collapsible soils. Consistent with the subsurface conditions under the distressed structures, it was planned to conduct constant-pressure (equivalent to the ground pressure exerted by boundary walls) laboratory plate load tests on collapsible soil to study the response of such light structures to changing water table levels occasioned by drip irrigation. The plate load tests were carried in two different cases as seen in Fig. 1.

In both cases, surface of the soil in the tank was loaded with a pressure equivalent to that exerted on the ground by the light structures and then settlements were observed with water infiltrating (simulating drip irrigation) from the surface. The tests were devised to help understand the settlement behavior of collapsible behavior of soil while the drip irrigation is underway. The influence of variable depths (simulating the actual groundwater table) of water the tank on time and magnitude of settlement was observed in case-1. In case-2, the influence of variable thickness of collapsible soil layer sandwiched between non-collapsible soil layers on time and magnitude of settlement was studied.

It is imperative that the laboratory test conditions represent the field situation as far as possible. Details of the experimental arrangement, materials and instrumentation specifications are described in the following sections.

Fig. 1 Plate load test cases

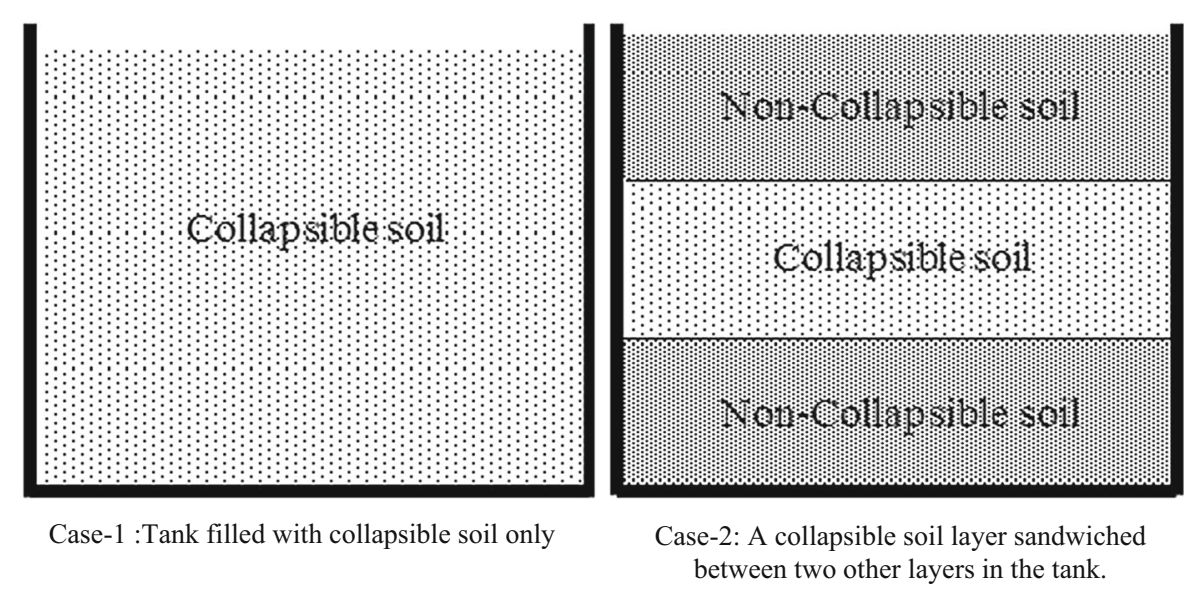




\subsection{Plate Load Test Set-Up}

A cubic tank measuring $1 \mathrm{~m} \times 1 \mathrm{~m} \times 1 \mathrm{~m}$ was fabricated using a mild steel sheet of $4 \mathrm{~mm}$ thick, with carefully designed joints to create a water-tight enclosure. The prepared tank was placed under a loading frame made from a steel beam of $250 \mathrm{~mm}$ width and $250 \mathrm{~mm}$ depth with mass per linear meter equal to $72.4 \mathrm{~kg} / \mathrm{m}$ and total mass of about $500 \mathrm{~kg}$ including the supports. This was done in order to act as a reaction while applying load on the soil using hydraulic jacks (Figs. 2, 3).

\subsection{Test Load Calculations}

As listed in Table 1, necessary calculations were made to derive the required weight of the loading frame

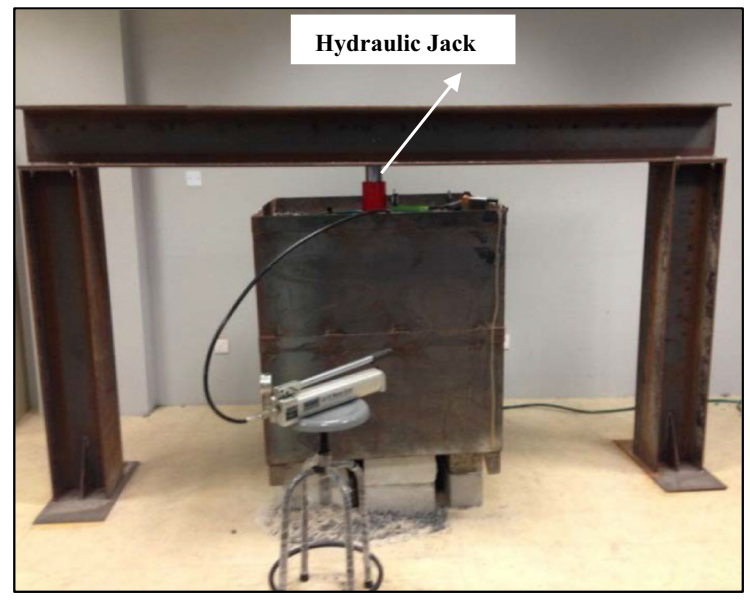

Fig. 2 Elevation of the experimental setup

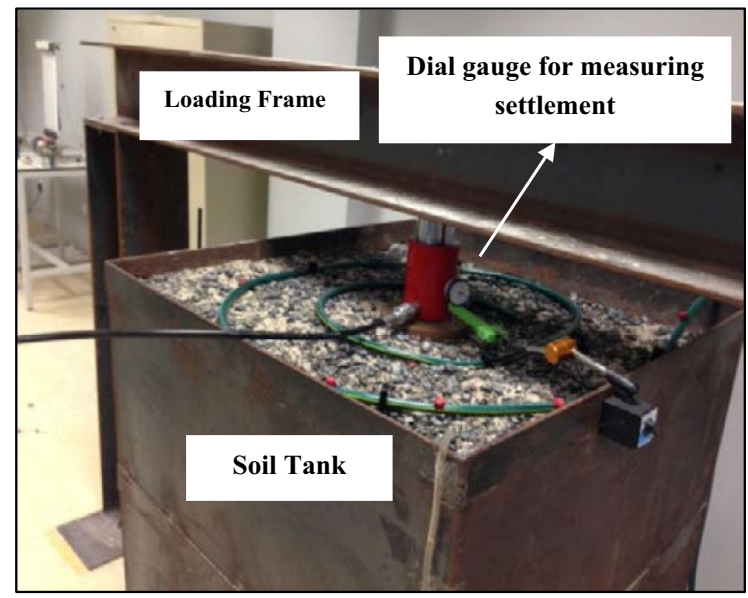

Fig. 3 The top view of the setup
Table 1 Minimum required reaction load for various stresses

\begin{tabular}{lll}
\hline Stress $\left(\mathrm{kN} / \mathrm{m}^{2}\right)$ & $\begin{array}{l}\text { Diameter of test } \\
\text { plate }(\mathrm{mm})\end{array}$ & $\begin{array}{l}\text { Minimum required } \\
\text { reaction load }(\mathrm{kg})\end{array}$ \\
\hline $50^{*}$ & 200 & 157 \\
100 & 200 & 315 \\
150 & 200 & 472 \\
\hline
\end{tabular}

sufficient to provide adequate reaction while testing the collapsible soil.

*Sample calculations

Stress $=50 \mathrm{kN} / \mathrm{m}^{2}$

Area of plate $=\pi r^{2}=3.14 *(0.01)^{2}=0.0314 \mathrm{~m}^{2}$

Reaction load required $(\mathrm{kg})=50 \times 1000 \times 0.0314 /$ $10=157 \mathrm{~kg}$

The dead weight of the loading frame used in the current work is $500 \mathrm{~kg}$ which evidently can resist a stress of up to $150 \mathrm{kN} / \mathrm{m}^{2}$. The emphasis was to simulate the behavior of collapsible soil strata in the field as realistically as possible. All plate load tests were conducted at a constant pressure of $80 \mathrm{kN} /$ $\mathrm{m}^{2}$ (calculated in accordance with the sizes, weights and foundations depths of various boundary walls and gazebos commonly used in the area of concern), which corresponds to the actual maximum pressure exerted on the ground by the kinds of installations cited above.

\subsection{Replication of Groundwater Table}

Many researchers have performed laboratory plate load tests but for either dry or fully saturated soils yet natural soils in the ground rarely fit this condition. So, it was considered more realistic to carry out model scale plate load tests with soil moisture contents and water table positions that relate to real field conditions. For this purpose, a hole was made on one side of the test tank and a piezometer inserted along with graduated scale to measure and control the water table level (Fig. 4). Initially water was poured into the empty tank to a depth of $10 \mathrm{~cm}$ from bottom and then dry soil was slowly added over the water. Furthermore, the placement of water and soil was done simultaneously until a stable water level in the tank was established.

\subsection{Preparation of Collapsible Soil}

Samples of collapsible soils were collected from various sites around Abu Dhabi, UAE, where 


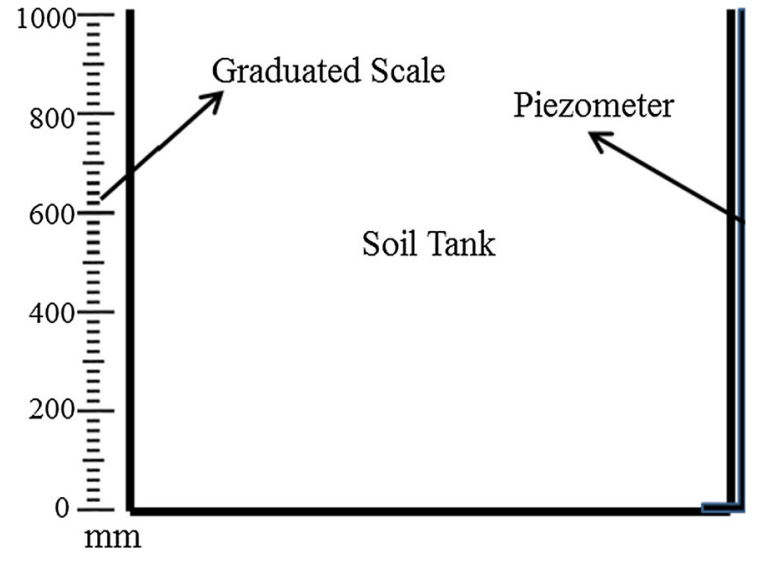

Fig. 4 Piezometer for monitoring water levels in the soil in tank

geotechnical companies had previously been contracted to undertake extensive investigations of structural distresses arising from ground movements. The main reason for the distress was subsoil collapse caused by ingress of irrigation water from the surrounding soft landscapes. The investigation companies drilled a number of boreholes, which showed that collapsible strata existed at depths where standard penetration test (SPT) values were low ( $\mathrm{N}=4$ to 10 ) and very low $(\mathrm{N}<4)$. It is from such depths where soil samples were collected for this research. The samples were analyzed using sieve tests (BS 1377-2:1990) to plot typical particle size distributions as shown in Fig. 5. The mean graph which closely represents the grain size distribution of all such soils was plotted and marked with a thick black curve in Fig. 5, along with SPT values and depths. The nomenclature followed in Fig. 5 is: depth, SPT N-value. For example (8-8.45 m, 9) indicates that the soil sample was obtained in respective borehole at a depth of $8.00-8.45 \mathrm{~m}$ using split spoon sampler and the SPT N-value recorded was 9.

Since filling the tank would require a large quantity of soil of specific gradation, a specialist company was contracted to grade the soil to required sizes on large scale basis using computer software. This facilitated production of 3 tons of soil fulfilling the desired gradation. In order to verify the software graded soil, random samples of the soil were subjected to laboratory sieving and found to be of acceptable particle size composition.

\subsection{Plate Load Test Details}

Initially the plate was set-up centrally beneath the loading frame and then a spirit level used to check and
Fig. 5 Grain size distribution

\section{GRAIN SIZE DISTRIBUTION OF SOILS WITH VERY LOW TO LOW RELATIVE DENSITIES}

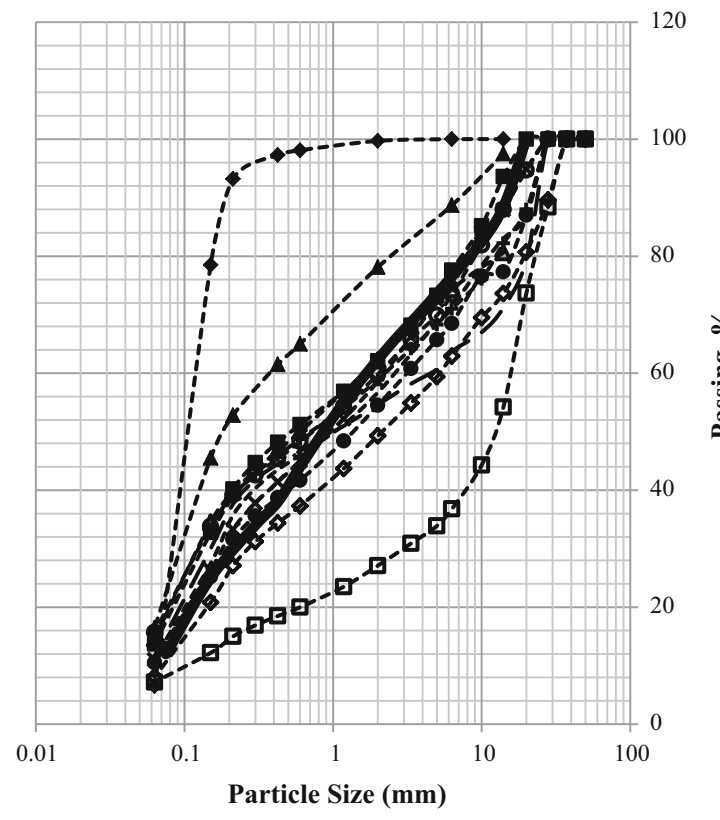

--\$-- borehole 1 (11-11.45m,8)

- $\boldsymbol{0}$-- borehole $2(8-8.45 \mathrm{~m}, 9)$

--^-- borehole $3(0-0.45 \mathrm{~m}, 6)$

--๑-- borehole 4(3-3.45m,10)

- $\rightarrow$-- borehole $5(8-8.45 \mathrm{~m}, 9)$

--x-- borehole $6(9-9.45 \mathrm{~m}, 10)$

-- -- borehole $8(0-0.45 \mathrm{~m}, 6)$

--+-- borehole $9(4-4.45,8)$

- - borehole $10(6-6.45 \mathrm{~m}, 10)$

-----borehole $12(0-0.45 \mathrm{~m}, 10)$

- - $\mathbf{-}$-- borehole 14 (1-1.45m,9)

--1-- borehole 15 (2-2.45m,9)

Collapsible Soil 
level the loading plate in horizontal position (Fig. 6). Once the plate had been set up correctly in position, a hydraulic jack was carefully placed over it and precisely below the loading frame. A dial gauge was then set up on the plate surface and mounted on a magnetic stand bearing on the side of the tank. Jack loads were then applied in increments equivalent to $1 / 10$ th to $1 / 12$ th of the targeted maximum pressure $\left(80 \mathrm{kN} / \mathrm{m}^{2}\right)$ until the final pressure was reached. Care was exercised to ensure that, at each load increment, the plate settlement reached a stable value before readings were recorded. Thereafter, wetting of soil was done in a controlled manner.

In view of understanding the effect of groundwater regime coupled with controlled irrigation on settlement of foundation, three plate load tests were carried out at different water levels as listed in Table 2. Once the first plate load test with groundwater level at 2.5B below the plate was conducted, the soil lying above the water level was removed from the tank and dried completely. The dried soil was then placed in the tank and water table raised to $1.5 \mathrm{~B}$ in order to proceed with

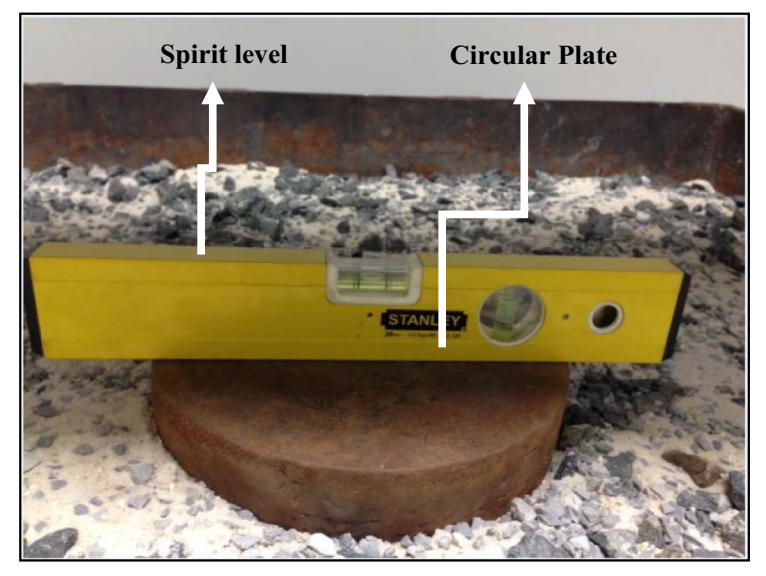

Fig. 6 Leveling the plate top

Table 2 Water table positions studied in plate tests

\begin{tabular}{ll}
\hline Test number & $\begin{array}{l}\text { Depth of water level below } \\
\text { bottom of plate }\end{array}$ \\
\hline 1 & $2.5 \mathrm{~B}(500 \mathrm{~mm})$ \\
2 & $1.5 \mathrm{~B}(300 \mathrm{~mm})$ \\
3 & $1.0 \mathrm{~B}(200 \mathrm{~mm})$ \\
\hline
\end{tabular}

$\mathrm{B}=$ diameter of plate $=200 \mathrm{~mm}$ the second test. The same procedure was also followed between the 2 nd (1.5B) and the 3rd (1.0B) tests.

In addition, four plate load tests at various collapsible soil to total soil stratum ratios $(1 / 2,1 / 3$, $1 / 4$ and 1/5) were carried out to understand the effect of collapsible soil as a layer in the soil strata. For this purpose, collapsible soil was inserted as a layer at the mid-depth and plate load test tests at constant pressure were conducted accordingly.

\subsection{Watering Pattern}

In order to create a laboratory simulation of the actual watering pattern due to irrigation of real landscapes, a pipe similar in diameter to the actual ones used in the UAE was prepared with perforations created at $15 \mathrm{~cm}$ intervals followed by fitting of drippers. The prepared pipe was placed on the surface of soil in the tank (Fig. 7) with one of its ends closed and the other connected to water supply. Once the targeted pressure of $80 \mathrm{kN} / \mathrm{m}^{2}$ was reached, water was allowed to flow in definite cycles. A 'cycle' is defined as application of specified quantity of water every $12 \mathrm{~h}$ for a duration of $30 \mathrm{~min}$. Drip irrigation was simulated over the soil in tank at the rate of $131 / \mathrm{m}^{2} /$ day (as per data obtained from local landscaping companies), watered twice a day (6.00 A.M.-6.30 A.M. and 6.00 P.M.-6.30 P.M.) equally at the rate of each $6.5 \mathrm{l} / \mathrm{m}^{2}$. Rate of discharge of water was ensured with the help of water-meter fitted at the water outlet and a stopwatch. Such cycles were continued until rate of increase in settlement was so fast that our primary aim of maintaining constant pressure was not possible.

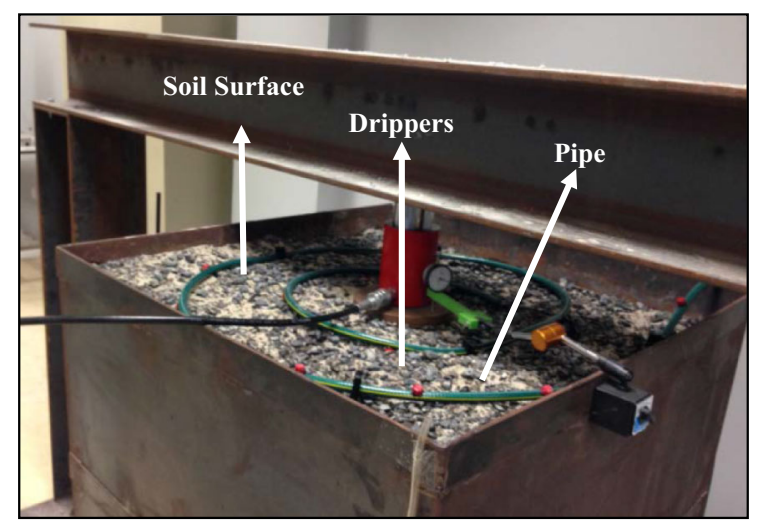

Fig. 7 Arrangement for simulating the field watering pattern 


\subsection{Constant Load Application Procedure}

In actual practice, once any lightly loaded structure is constructed, its dead weight is largely constant throughout the lifetime, any live loads on such a structure being relatively small. On this basis, it was considered that the plate load tests ought to be conducted with maintained ground pressure to simulate the condition of a bearing soil medium. Once the dripping of water was initiated the soil started losing its strength due to the collapse of its structure which resulted in a decrease in the pressure exerted on the soil. Such a reduction in pressure was immediately compensated by manually applying pressure via the lever of the hydraulic jack (Fig. 8). This was possible due to continuous monitoring of pressure while applying the desired watering cycles on the soil surface.

\section{Test Results and Discussions}

All outcomes obtained from constant load plate load tests were elucidated in forthcoming sections.

\subsection{Plate Load Tests-Full Collapsible Soil}

Three plate load tests were carried out at different water levels as listed in Table 2. The water depths beneath the bottom of test plate were chosen to be consistent in scale to the actual foundation situations at the locations where structural distresses were investigated in the UAE case studies. Data from the plate

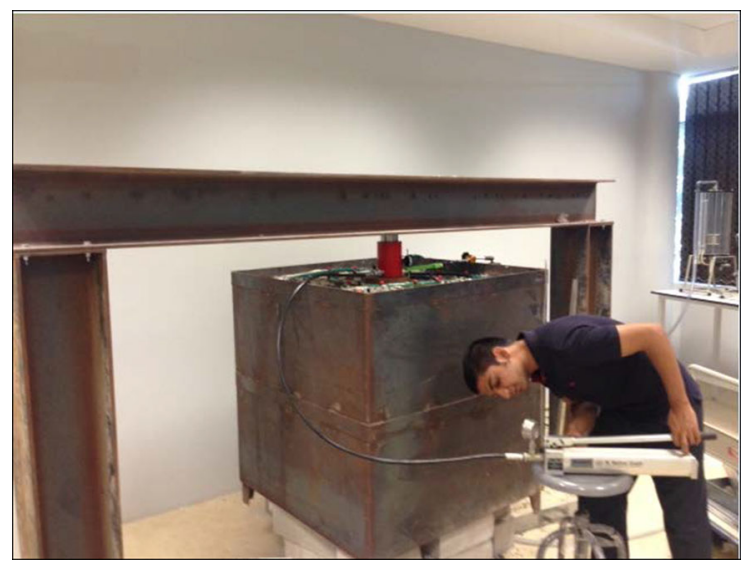

Fig. 8 Maintaining constant pressure load tests were transferred into Microsoft Excel workbooks for further processing in a bid to study the underlying patterns. Graphs of pressure against settlement and of settlement versus time were plotted and are discussed in the following sections.

\subsubsection{Effect of Dripping Water on Settlement of Soil}

Pressure-settlement graphs for all three tests conducted are shown in Figs. 9, 10, and 11. It was also observed that the number of wetting cycles required for the soil to reach collapsing state increased with increase in the depth of the water table below the plate

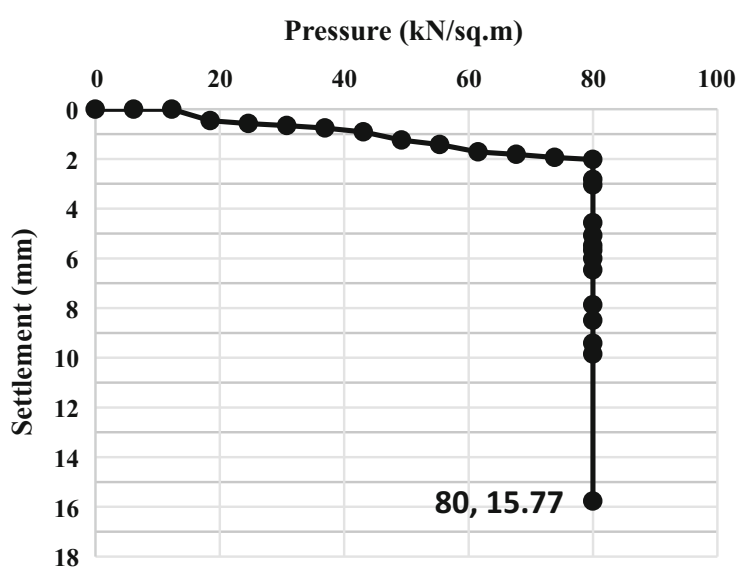

Fig. 9 Pressure-settlement curve with groundwater table at depth of $2.5 \mathrm{~B}$

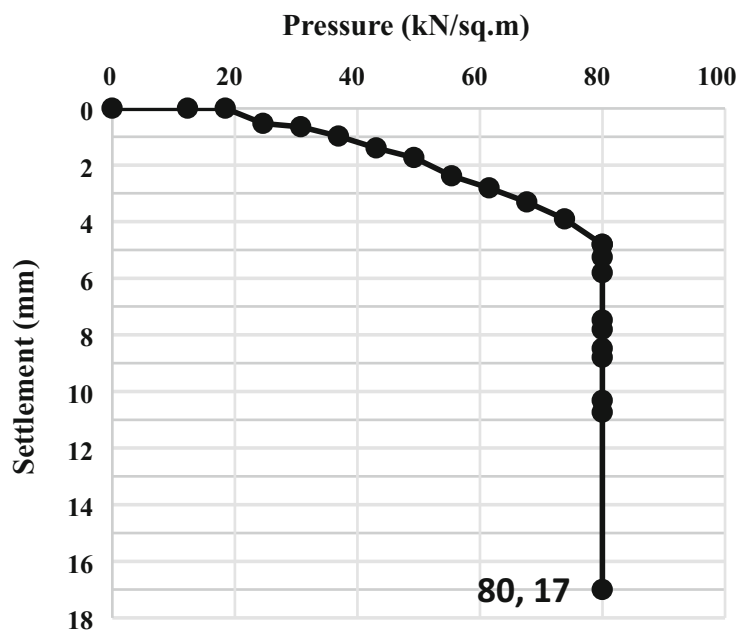

Fig. 10 Pressure-settlement curve with groundwater table at depth of $1.5 \mathrm{~B}$ 


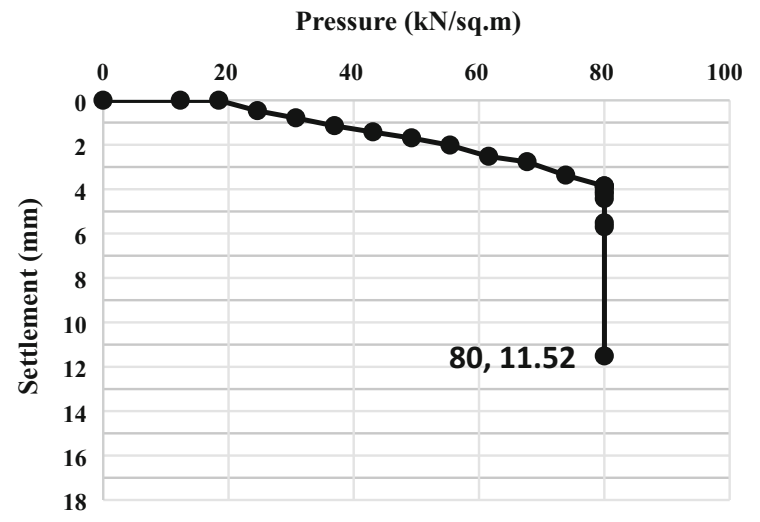

Fig. 11 Pressure-settlement curve with groundwater table at depth of 1.0B

Table 3 Wetting cycles before collapse

\begin{tabular}{ll}
\hline $\begin{array}{l}\text { Depth of groundwater level below } \\
\text { foundation }\end{array}$ & $\begin{array}{l}\text { Number of wetting } \\
\text { cycles }\end{array}$ \\
\hline $2.5 \mathrm{~B}$ & 7 \\
$1.5 \mathrm{~B}$ & 5 \\
$1.0 \mathrm{~B}$ & 4
\end{tabular}

' $\mathrm{B}$ ' refers to width of foundation (width of plate in the plate load test)

(Table 3). This could be attributed to the presence of a deeper zone of soil (2.5B) involved in the collapse mechanism when the water level is at $2.5 \mathrm{~B}$, where the number of wetting cycles needed to cause soil collapse was greatest in comparison to the other cases. It is also apparent that the further the collapsible soil zone is below the plate foundation the higher is the number of cycles of wetting necessary to initiate soil collapse.

\subsubsection{Effect of Time on Settlement of Soil}

Time-settlement graphs for all three tests carried out are shown in Fig. 12. The graphs illustrate that the time required for the soil to exhibit its collapse behavior increases with increase in thickness of collapsible soil below the plate foundation. The time durations from commencement of test to start of soil collapse are listed in Table 4 for brevity and ease of understanding. A linear behavior is evident from the data in Table 4, so that a $0.5 \mathrm{~B}$ increase in depth of water is equivalent to a time gap of $60 \mathrm{~min}$ between the start of test and the onset of soil collapse.

\subsubsection{Rate of Collapse}

As previously stated, each plate load test was terminated once settlement rate was so rapid that the prime objective of maintaining constant pressure cannot be continued. To understand the rate of collapse, the time-settlement data of the last wetting cycle from each test was used to calculate the rate of collapse. The calculations and corresponding results are shown in Table 5. It is evident that irrespective of the thickness of collapsible soil below the base of the plate, the rate of collapse exhibited by the soil in all three tests was fairly uniform at $6 \mathrm{~mm}$ in $30 \mathrm{~min}(0.2 \mathrm{~mm} / \mathrm{min})$.
Fig. 12 Time-settlement curves at various groundwater levels

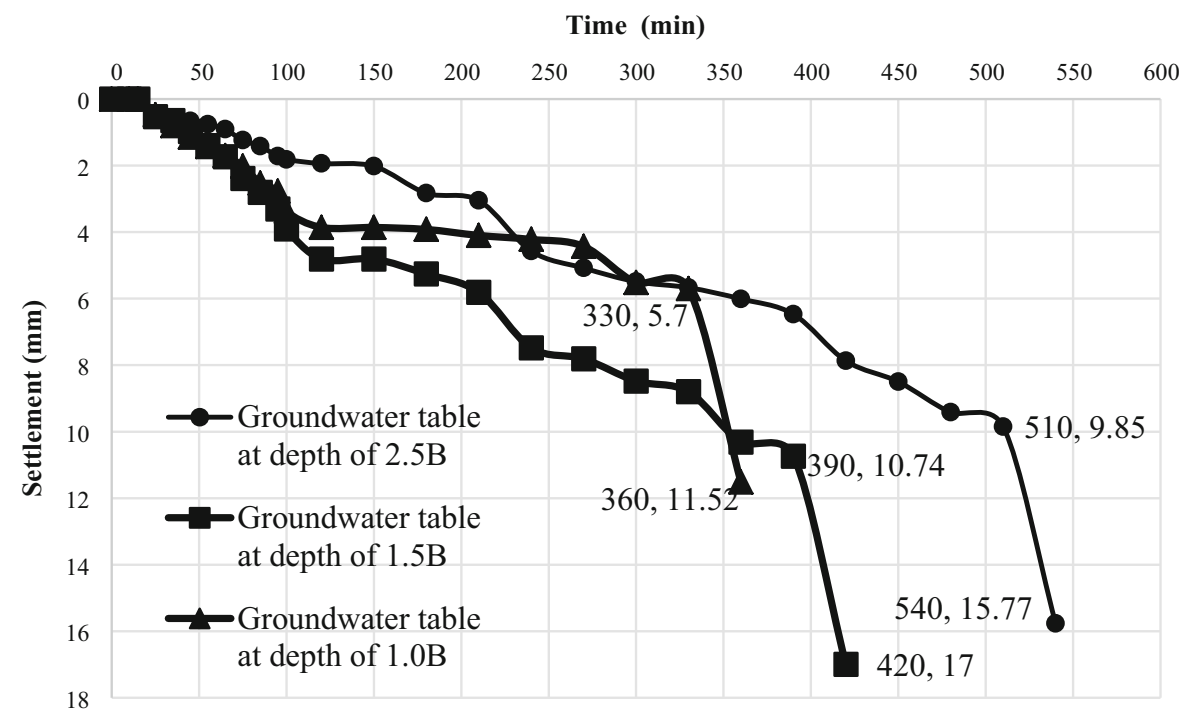


Table 4 Time taken to achieve soil collapse

\begin{tabular}{ll}
\hline Depth of groundwater table & Time (min) \\
\hline $2.5 \mathrm{~B}$ & 510 \\
$1.5 \mathrm{~B}$ & 390 \\
$1.0 \mathrm{~B}$ & 330 \\
\hline
\end{tabular}

' $\mathrm{B}$ ' refers to width of foundation (width of plate in the plate load test)

\subsubsection{Effect of Loading-Reloading on Modeled Groundwater Table}

Each time, once the soil was removed and replaced after drying, there was a drop in water level in the piezometer when weight was placed on the soil. To understand this behavior moisture content and specific gravity of soil after removing the soil was determined before replacing it with dry soil and was found to be $12 \%$ and 2.6 respectively. Compaction test (BS 1377-4:1990) was conducted on collapsible soil and the resulting curve plotted as shown in Fig. 13. It was interesting to note that the soil was not compacted to maximum dry deity (MDD) although it was on the path towards attaining it, with placement of more soil over. Calculations to support this observation are shown below.

From compaction test (Fig. 13)

$\mathrm{OMC}=15.5 \%, \mathrm{MDD}=18.45 \mathrm{kN} / \mathrm{m}^{2}$

At MDD, $\gamma_{d=G \gamma_{w /(1+e)}}$

$18.45=(2.6 \times 10) /(1+\mathrm{e})$

$\mathrm{e}=0.4$

$$
\text { Now } \begin{aligned}
s & =\frac{w G}{e}=(15.5 / 100) \times 2.6 / 0.4=0.983 \\
& =98.3 \%
\end{aligned}
$$

At $12 \%$ moisture content, $\gamma_{d}=17.8 \mathrm{kN} / \mathrm{m}^{3}$

$$
\begin{aligned}
& \gamma_{d=G \gamma_{w /(1+e)}} \\
& 17.80=(2.6 \times 10) /(1+\mathrm{e}) \\
& \mathrm{e}=0.46
\end{aligned}
$$

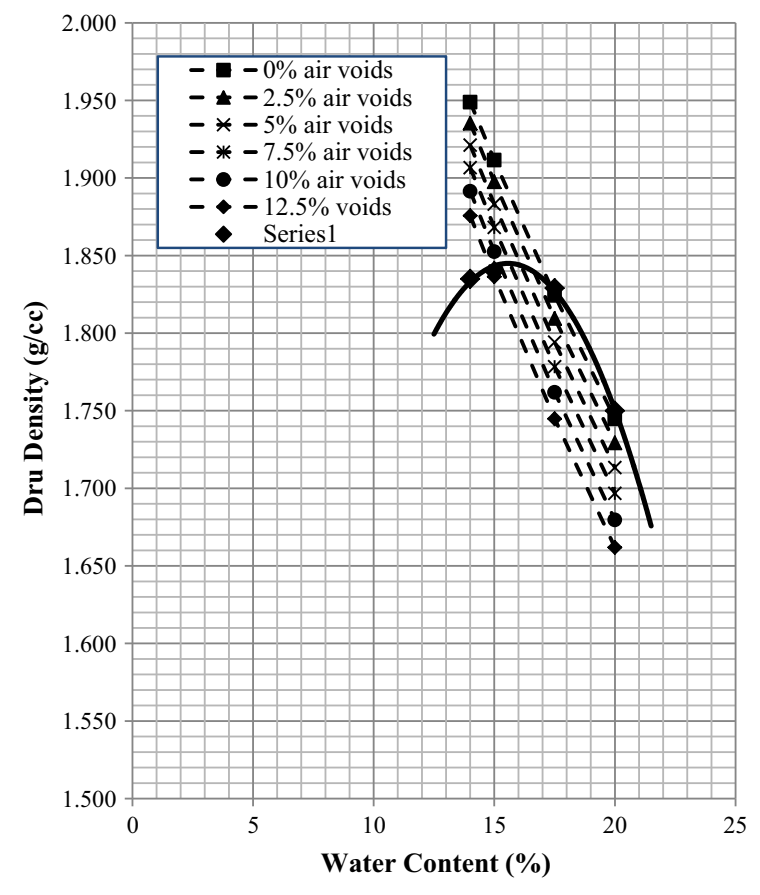

Fig. 13 Compaction curve

$s=\frac{w G}{e}=(12 / 100) \times 2.6 / 0.46=0.68(68 \%)$

From the calculations it was inferred that the downward movement in water level due to placement of weight (soil) was attributable to the relief of pore pressure in the voids within the partially saturated soil ( $\mathrm{S}=68 \%$ ) as it transited to a fully saturated condition.

\subsection{Plate Load Tests-Collapsible Soil as a Layer}

In this part of the work, permeability tests (BS 1377-5:1990) and laboratory plate load tests were conducted for a layered soil profile containing a collapsible soil lens, of variable thickness, inserted at mid-depth of the soil stratum below the plate. The layered soil profile acted as a bearing medium to simulate ground support for a superstructure. The results from all permeability tests are plotted against

Table 5 Settlement rate calculations

\begin{tabular}{lclll}
\hline $\begin{array}{l}\text { Depth of groundwater } \\
\text { table }\end{array}$ & $\begin{array}{l}\text { Settlement of soil before } \\
\text { the start of collapse }(\mathrm{mm})\end{array}$ & $\begin{array}{l}\text { Settlement at the } \\
\text { end of test }(\mathrm{mm})\end{array}$ & $\begin{array}{l}\text { Time between start of collapse } \\
\text { and end of test (min) }\end{array}$ & $\begin{array}{l}\text { Collapse } \\
\text { settlement (mm) }\end{array}$ \\
\hline $2.5 \mathrm{~B}$ & 9.85 & 15.77 & 30 & 5.92 \\
$1.5 \mathrm{~B}$ & 10.74 & 17.00 & 30 & 6.26 \\
$1.0 \mathrm{~B}$ & 5.70 & 11.52 & 30 & 5.82 \\
\hline
\end{tabular}


Fig. 14 Thickness of collapsible layer versus permeability
$\mathrm{X}=$ Thickness of collapsible soil $(\mathrm{mm})$

$\mathrm{H}=$ Total height of soil in permeameter $(\mathrm{mm})$

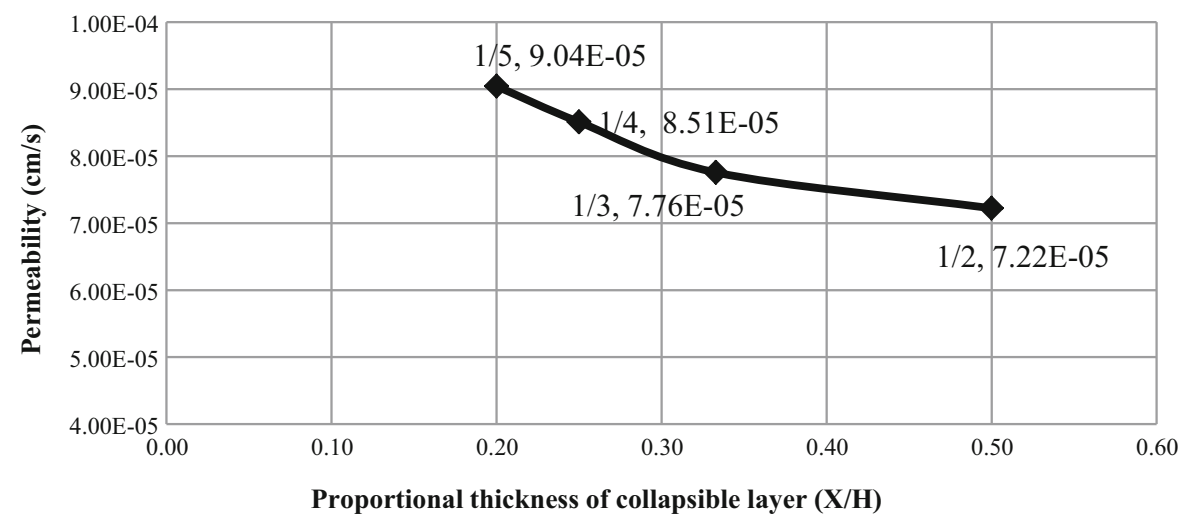

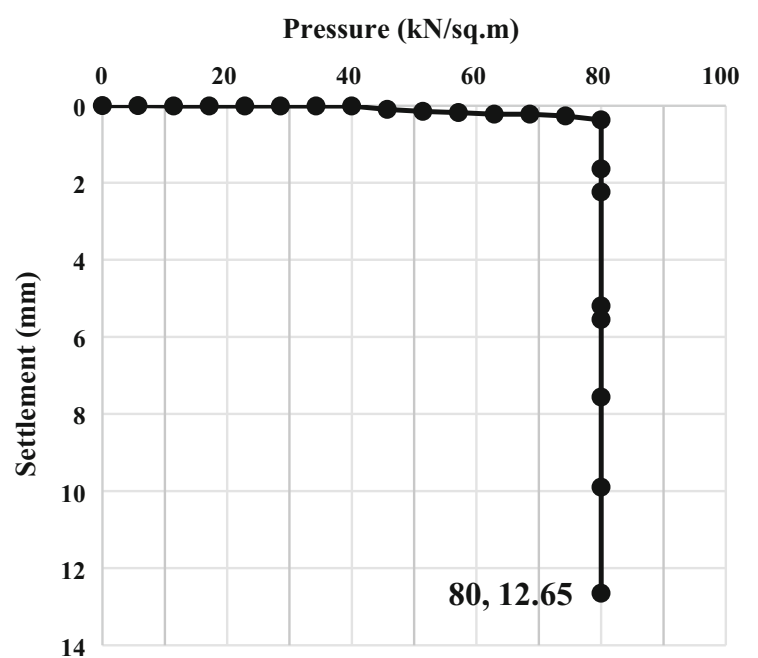

Fig. 15 Pressure versus settlement with collapsible soil at central half of the tank

the thickness of collapsible soil layer in order to understand its behavior. Results from all plate load tests were also presented graphically. For this purpose various pressure-settlement and time-settlement graphs were constructed and are discussed in the next sections.

\subsubsection{Effect of Permeability on Thickness of Collapsible Soil Layer}

It is observed (Fig. 14) that there is a decrease in permeability of the soil with increase in thickness of the collapsible layer. This could be attributed to the increase in density of collapsible soil due to inward movement of water consequently leading to a decrease

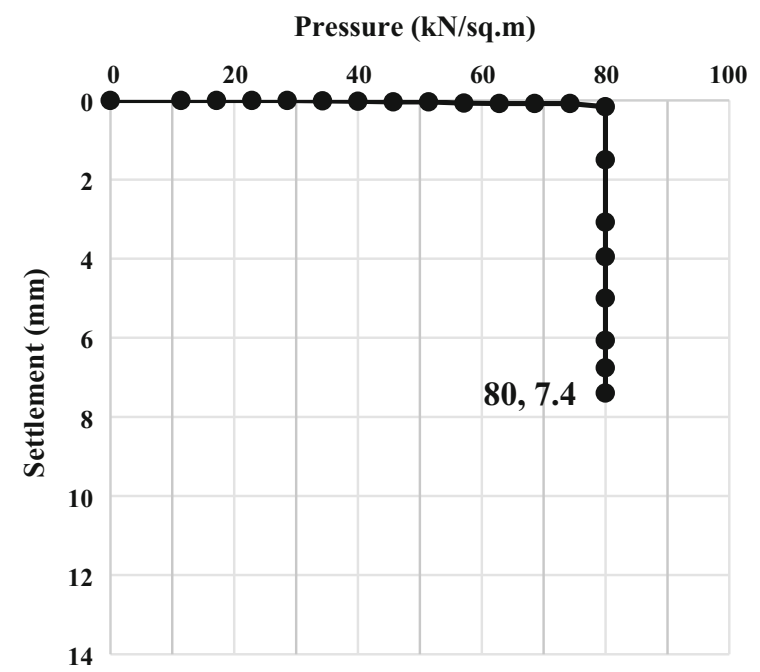

Fig. 16 Pressure versus settlement with collapsible soil at central $1 / 3$ rd of the tank

in permeability as the collapsible layer thickness increases.

\subsubsection{Effect of Dripping Water on Settlement of Soil}

It can be seen from the graphs in Figs. 15, 16, 17, and 18 that settlement decreases with decreasing thickness of the collapsible soil layer. This is expected because it is the collapsible layer and its thickness (rather than other layers) that are responsible for settlement under these situations. The relationship between settlement and thickness of collapsible soil is illustrated by the graph in Fig. 19. The variation trend line is represented by Eq. (1), which can be applied to a real problem in predicting settlement due to collapsible 
Pressure (kN/sq.m)

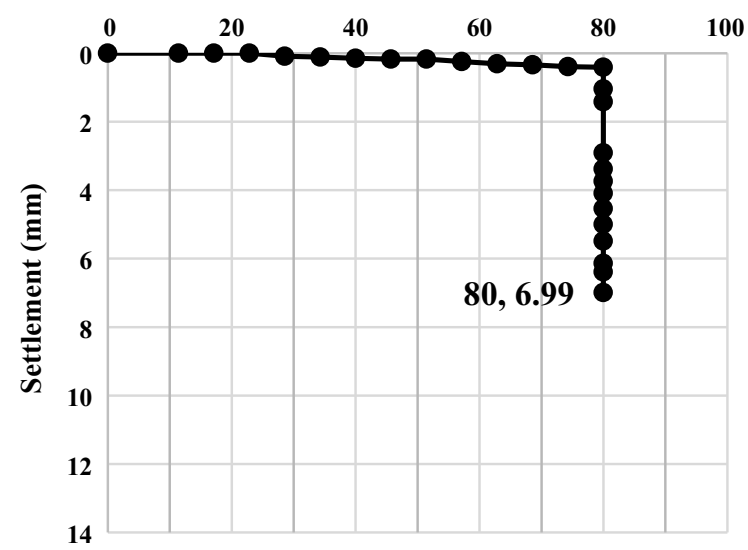

Fig. 17 Pressure versus settlement with collapsible soil at central $1 / 4$ th of the tank

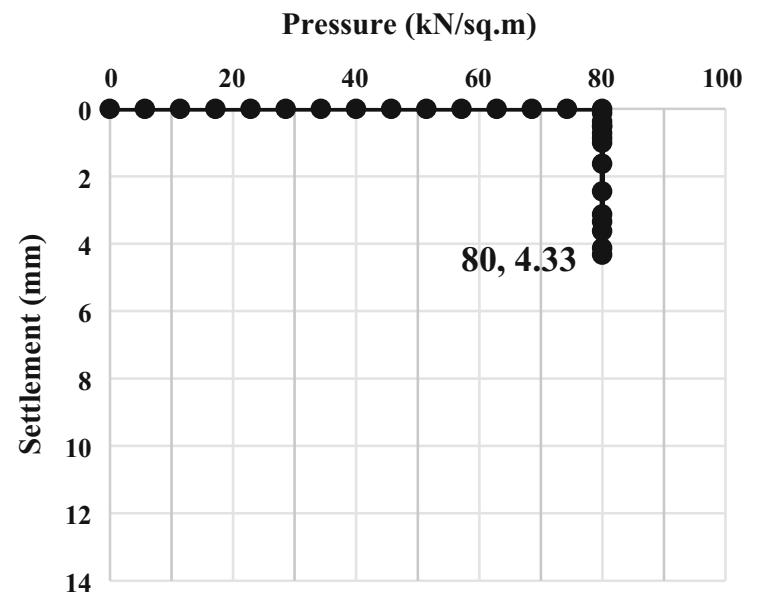

Fig. 18 Pressure versus settlement with collapsible soil at central $1 / 5$ th of the tank
Thickness of Collapsible Soil Layer (mm)

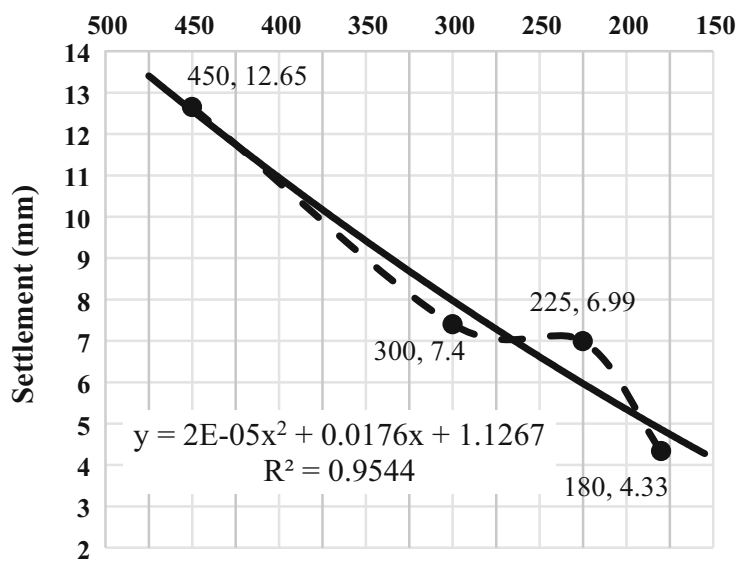

Fig. 19 Thickness of collapsible soil layer versus settlement

soil behavior, provided the proportionate thickness of the collapsible soil is known.

$\mathrm{y}=2 \mathrm{E}-05 \mathrm{x}^{2}+0.0176 \mathrm{x}+1.1267$

where $\mathrm{x}=$ thickness of collapsible soil (mm); $\mathrm{y}=$ settlement $(\mathrm{mm})$

\subsubsection{Effect of Time on Settlement of Soil}

Time-settlement graphs for all plate load tests conducted are shown in Fig. 20. It is seen that in all cases, settlement increases with time but at different rates depending on the position and thickness of the collapsible soil relative to the tank depth. This is again attributed to the proportionate influence of collapsible

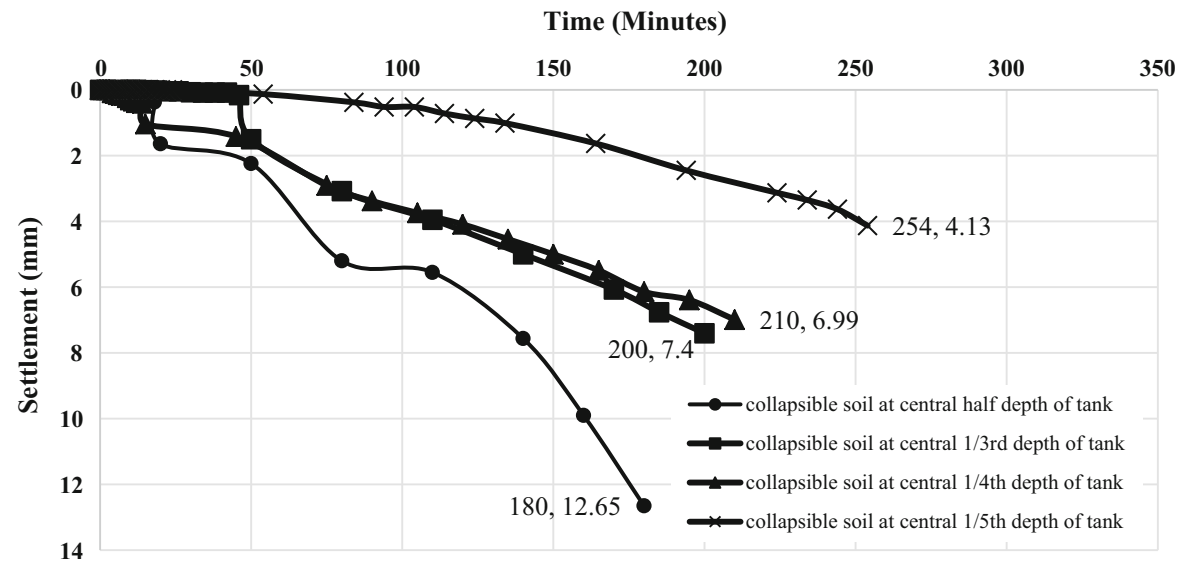

Fig. 20 Time versus settlement with various collapsible soil thicknesses at central depth of tank 


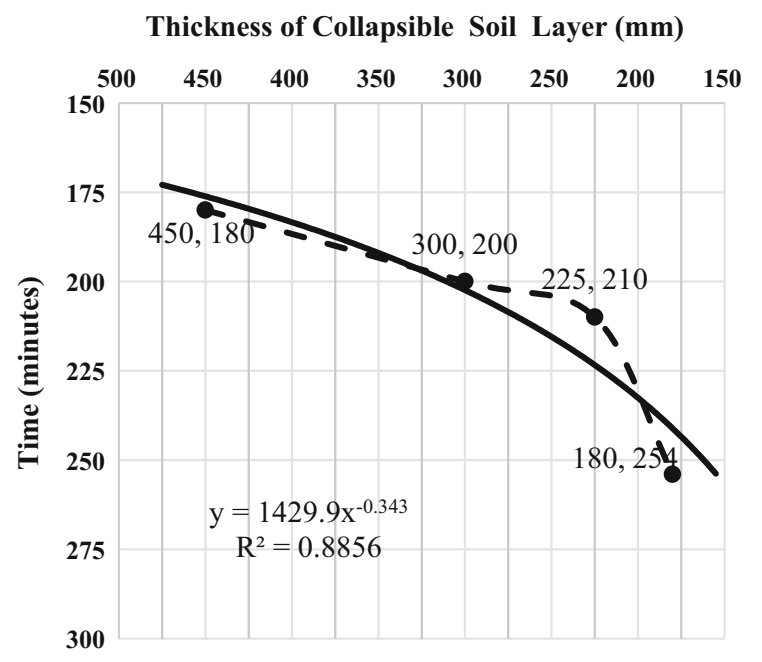

Fig. 21 Thickness of collapsible soil layer versus time

soil responsible for settlement. The relationship between time and thickness of collapsible soil is shown in Fig. 21, where the trend of variation represented by Eq. (2).

$\mathrm{y}=1429.9 \mathrm{x}^{-0.343}$

where $\mathrm{y}=$ time $(\mathrm{min}) ; \mathrm{x}=$ thickness of collapsible soil $(\mathrm{mm})$

Equation (2) may be used to predict the time taken by the soil to exhibit settlement if proportionate thickness and depth location of the collapsible soil is known.

\section{Conclusions}

1. The number of wetting cycles required for the soil to exhibit the collapse increases with increase in depth of groundwater table below the foundation level.

2. Once the soil starts exhibiting its collapsible behavior, the rate at which it collapses was found to be uniform irrespective of its thickness.

3. The decrease in water level in the soil due to placing the soil (after removing) could be attributed to the removing pressure which being exerted by the air in air voids on the voids that are partially saturated to reach into a fully saturated conditions.

4. The permeability of the soil stratum decreases with increase in thickness of collapsible soil portion in it.

5. The magnitude of settlement increases with increased proportion of collapsible soil in a soil strata.

6. The time required for the soil to start exhibiting collapse increases with increasing depth of the groundwater table below the foundation. In addition, despite high magnitudes of ground settlement, the time required to attain the maximum settlement decreases with increase in the thickness of the collapsible stratum.

7. Predictive relationships were developed for linking the time period for maximum settlement to thickness of collapsible soil as well as magnitude of settlement to thickness of collapsible layer. These relationships can be used by geotechnical engineers to assess the rate and magnitude of settlements, depending on the thickness of the collapsible soil at a particular site. Though every effort has been made in the current study to prepare sufficiently large sized models to simulate field conditions relevant to the UAE case studies, inevitably there will be variations to be taken into account from one site to another. These variations include: the rate and frequency of irrigation, thickness of collapsible soil stratum and its depth below ground level as well as depth of groundwater table. Thus, geotechnical engineers need to exercise utmost care when assessing the important parameters such as time, rate and magnitude of collapse settlements in the particular locality of concern. A reliable assessment of the relationship between the intensity of landscape irrigation, water table level, thickness and location of collapsible strata can enable UAE geotechnical engineers to develop guidance for property owners/members of the public to help them control rates of irrigation hence avoid extreme ground settlement that would cause structural distress of the kind reported in the case studies in this paper.

The current laboratory test results will form part of an ongoing doctoral research project aimed at assess- 
ing the behavior of collapsible soil under various structural loads. In addition, numerical analysis using finite element methods is planned to carryout in view of understand the behavior on large scale, whereby eventual aim is to develop equations and course of actions that geotechnical engineers may find useful while performing geotechnical analysis of structures resting on collapsible soil layers.

Open Access This article is distributed under the terms of the Creative Commons Attribution 4.0 International License (http:// creativecommons.org/licenses/by/4.0/), which permits unrestricted use, distribution, and reproduction in any medium, provided you give appropriate credit to the original author(s) and the source, provide a link to the Creative Commons license, and indicate if changes were made.

\section{References}

Abbeche K, Bahloul O, Ayadat T, Bahloul A (2010) Treatment of collapsible soils by salts using the double consolidation method. In: Proceedings of international conference GeoShanghai, Shanghai, China, ASCE, Reston, VA, USA

Anderson SA, Riemer MF (1995) Collapse of saturated soil due to reduction in confinement. J Geotech Eng 121(2):216219. doi:10.1061/(ASCE)0733-9410(1995)

Gaaver KE (2012) Geotechnical properties of Egyptian collapsible soils. Alex Eng J 51:205-210. doi:10.1016/j.aej. 2012.05.002

Holtz WG, Hilf JW (1961) Settlement of soil foundations due to saturation. In: Proceedings of 5th international conference on soil mechanics and foundation engineering, vol 1. Paris, pp 673-679

Houstan SL, Houston WN, Lawrence CA (2002) Collapsible soil engineering in highway infrastructure development. J Transp Eng 128(3):295-300. doi:10.1061/(ASCE)0733947X(2002)

Houston WN, Mahmoud HH, Houston SL (1993) Laboratory procedure for partial-wetting collapse determination, unsaturated soils, ASCE, New York, USA, Special Geotechnical Publication vol 39, pp 54-63

Houston SL, Hisham HHM, Houston WN (1995) Down-hole collapse test system. J Geotech Eng 121(4):341-349. doi:10.1061/(ASCE)0733-9410(1995)
Jasmer R, Ore HB (1987) Hydro-compaction hazards due to collapsible loess in South-Eastern Idaho. Proceedings of the 23rd symposium on engineering geology and soils engineering. Logan, Utah, pp 461-475

Jennings JE, Knight K (1975) A guide to construction on or with materials exhibiting additional settlements due to collapse of grain structure. In: Proceedings of 6th regional conference for Africa on soil mechanics and foundation engineering, Johannesburg, pp 99-105

Jotisankasa A (2005) Collapse behavior of a compacted silty clay. Ph.D. Thesis, Imperial College, London

Kalantari B (2012) Foundations on collapsible soils: a review. Proc inst civ eng Forensic Eng 166(FE2):57-63. doi:10. 1680/feng.12.00016

Leroueil S, Vaughan PR (1990) The general and congruent effects of structure in natural soils and weak rocks. Geotechnique 40(3):467-488. doi:10.1680/geot.1990.40. 3.467

Murthy VNS (2010) Soil mechanics and foundation engineering. CBS publishers and distributors, New Delhi

Noutash MK, Hajialilue BM, Cheshmdoost M (2010) Prepounding of canals as a remediation method for collapsible soils. In: Proceedings of the 4th international conference on geotechnical engineering and soil mechanics, Tehran, Iran

Pye K, Tsoar H (1990) Aeolian sand and sand dunes. Unwin Hyman, London

Rezaei M, Ajalloeian R, Ghafoori M (2012) Geotechnical properties of problematic soils: emphasis on collapsible cases. Int J Geosci 3(1):105-110. doi:10.4236/ijg.2012. 31012

Reznik YM (1993) Plate-load tests of collapsible soils. J Geotech Eng 119(3):608-615. doi:10.1061/(ASCE)07339410(1993)

Reznik YM (2007) Influence on physical properties on deformation characteristics of collapsible soils. Eng Geol 92(1-2):27-37. doi:10.1016/j.enggeo.2007.03.001

Vandanapu R, Omer JR, Attom MF (2016) Geotechnical case studies: emphasis on collapsible soil cases. Proc Inst Civ Eng Forensic Eng 169(3):103-110. doi:10.1680/jfoen.16. 00011

Wesley LD (1990) Influence of structure and composition of residual soils. J Geotech Eng ASCE 116(4):589-603. doi:10.1061/(ASCE)0733-9410(1990)

Zhu Y, Chen Z (2009) A new method of studying collapsibility of loess. Front Archit Civ Eng China 3(3):305-311. doi:10. 1007/s11709-009-0040-3 